Available online on 15.11.2015 at http://jddtonline.info

Journal of Drug Delivery and Therapeutics

Open access to Pharmaceutical and Medical research

(C) 2015, publisher and licensee JDDT, This is an Open Access article which permits unrestricted noncommercial use, provided the original work is properly cited

RESEARCHARTICLE

\title{
MOLECULAR CONFIRMATION, IDENTIFICATION AND INFLUENCE OF CARBON SOURCE FOR THE PRODUCTION OF XYLANASE FROM PENICILLIUM CITRINUM
}

\author{
Naveen $\mathbf{M}^{1}$ and $*$ Siddalingeshwara $\mathbf{K ~ G}^{\mathbf{2}}$ \\ ${ }^{1}$ Research and Development Centre, Bharathiar University, Coimbatore, India \\ ${ }^{2}$ Scientific \& Industrial Research Centre, Bangalore, India
}

Received 16 Oct 2015; Review Completed 12 Nov 2015; Accepted 12 Nov 2015, Available online 15 Nov 2015

\begin{abstract}
Recently, xylanases have expanded their use in many processing industries, such as pulp and paper, food and textile to newer needs such as biofuel production. .This study were taken up to the enhance the biosynthesis of xylanase by supplementation of carbon sources were employed in range of $0.25 \%$ to $1.0 \%$. The carbon source were supplemented are glucose, sucrose and maltose. The beef extract and ammonium nitrate were yielded higher xylnase production and showed 7.5 IU and $8.4 \mathrm{IU}$
\end{abstract}

Key words: Xylanase, submerged fermentation, xylose, fermentation kinetics and inoculums size

\section{INTRODUCTION}

Until recently, in the pulp and paper industry, the use of enzymes was not considered technically or economically feasible. Quite simply, suitable enzymes were not readily available, except for limited use in the modification of starch for paper coatings. However, research by scientific institutions and enzyme producers has led to the development of enzymes that offer significant benefits for the industry. Several commercial products have been launched successfully in the past few years.

The enzyme, xylanase are the upcoming enzyme of commercial sector and are widely used in paper and pulp industry, animal feed, textile industry, coffee and tea fermentation, oil extraction, waste paper recycling and in the fruit juice industries. This enzyme are the tools of nature that help us in providing everyday products in an environmentally conscious manner.

Xylanases are hydrolases depolymerising the plant cell wall component-xylan, the second most abundant polysaccharide. The Molecular structure and hydrolytic pattern of the xylanases have been reported extensively and mechanism of hydrolysis has also been proposed ${ }^{1}$.

Many different microbial genera, ranging from bacteria to fungi, have been found to produce one or several xylanases ${ }^{2}$. Fungal species known to produce xylanase include Aspergillus, Disporotrichum, Pencillium, Neurospora, Fusarium, Trichoderma, etc. ${ }^{3}$. Filamentus fungi have been used for more than 50 years in the production ofindustrial enzymes ${ }^{4}$. They are particularly interesting producers of xylanases and excrete much higher xylanolytic enzymes into the medium than bacteria or yeast ${ }^{5}$.

Due to importance of xylanase production, we made an effort to produce xylanase from Penicillium citrinum through submerged fermentation, achieved an enhanced level production of xylanase by supplementation carbon source were. The molecular identification of fungal strain was added.

\section{MATERIALS AND METHODS}

\section{Fungal Strain}

The Penicillium citrinum strains were isolated from different soils. Soils are taken from different regions from in and around Bangalore and tentatively identified in the laboratory

*Corresponding Address:

Dr. Siddalingeshwara $K G$ Head-Research and Development Scientific \& Industrial Research Centre, Yeshwantapur, Bangalore, India-560022 E-mail: siddha_lingeshwar@rediffmail.com 


\section{Screening of Xylanase Producers}

Penicillium citrinum strains were screened for their xylanase activity by plate assay ${ }^{6}$. (Plate-1) and among the thirty isolates, Penicillium citrinum KGSN 05 were used for further studies. The selected Penicillium citrinum KGSN 05 were confirmed at molecular level in next steps.

\section{IDENTIFICATION AND CONFIRMATION OF FUNGAL STRAIN BY MOLECULAR LEVEL}

\section{i. DNA extraction:}

The genomic DNA was isolated from the given fungus using fungus genomic DNA extraction Kit.

\section{ii. PCR Amplification:}

\section{a. Amplification of the ITS region (ITS1, ITS2, and 5.8 S rRNA Gene)}

Amplification of the ITS region (ITS1, ITS2, and 5.8 S

rRNA Gene) was performed using the

Universal primers ITS1 and ITS4

Primer ITS1: 5'- TCCGTAGGTGAACCTGCGG-3'

Primer ITS4: 5' - TCCTCCGCTTATTGATATGC-3'

PCR was performed as follows in a total volume of $50 \mu \mathrm{l}$ in a $0.2 \mathrm{ml}$ thin walled PCR tube.

\begin{tabular}{|l|l|}
\hline Components & Volume \\
\hline Nuclease free water & $37 \mu \mathrm{l}$ \\
\hline Genomic DNA $(0.1 \mu \mathrm{g} / \mu \mathrm{l})$ & $2.0 \mu \mathrm{l}$ \\
\hline Forward Primer $(10 \mu \mathrm{M})$ & $2.0 \mu \mathrm{l}$ \\
\hline Reverse Primer $(10 \mu \mathrm{M})$ & $2.0 \mu \mathrm{l}$ \\
\hline $10 X$ Reaction Buffer & $5.0 \mu \mathrm{l}$ \\
\hline dNTP Mix $(10 \mathrm{mM})$ & $1.5 \mu \mathrm{l}$ \\
\hline Taq DNA polymerase $(5 \mathrm{U} / \mu \mathrm{l})$ & $0.5 \mu \mathrm{l}$ \\
\hline Total volume & $50 \mu \mathrm{l}$ \\
\hline
\end{tabular}

The amplification was carried out in a Master cycler $^{\circledR}$ Thermocycler (Eppendorf, Germany) using the following program.

Initial denaturation of $94^{\circ} \mathrm{C}$ for 2 minutes followed by 40 cycles of denaturation at $94^{\circ} \mathrm{C}$ for $1 \mathrm{~min}$, annealing at $55.5^{\circ} \mathrm{C}$ for $1 \mathrm{~min}$ and extension at $72^{\circ} \mathrm{C}$ for $30 \mathrm{sec}$. Final extension was carried out at $72^{\circ} \mathrm{C}$ for $10 \mathrm{~min}$. The $\sim 600$ bp PCR products were purified to remove unincorporated dNTPS and Primers before sequencing using PCR purification kit (Norgen Biotek, Canada).

\section{iii. Sequencing:}

Both strands of the rDNA region amplified by PCR were sequenced by automated DNA sequencer -3037xl DNA analyzer from Applied Biosystems using BigDye ${ }^{\circledR}$ Terminator v3.1 cycle sequencing Kit (Applied Biosystems). Sequence data were aligned and dendrograms were generated using Sequence analysis software version 5.2 from applied biosystems. The sequences obtained for plus and minus strands were aligned using DNA baser program before performing the bioinformatics analysis.

\section{iv. Bioinformatics analysis:}

Sequences were compared to the non-redundant NCBI database by using BLASTN, with the default settings used to find the most similar sequence and were sorted by the $\mathrm{E}$ score. A representative sequence of 10 most similar neighbors was aligned using CLUSTAL W2 for multiple alignment with the default settings. The multiplealignment file was then used to create phylogram using MEGA5 software.

\section{INFLUENCE OF CARBON SOURCE FOR THE BIOSYNTHESIS OF XYLANASE}

A set of conical flasks with $100 \mathrm{ml}$ of production medium supplemented with a particular carbon source with concentrations ranging from $0.25 \%$ to $1.0 \%$ with increments of $0.25 \%$. The different carbon sources like, monosaccharides (glucose) and disaccharides (Maltose and sucrose) were used under the present study.

The production medium consists $(\mathrm{mg} / 100 \mathrm{ml})$ of sucrose 3 , di potassium hydrogen phosphate $0.1, \mathrm{MgSO}_{4}, 0.05 \mathrm{~g}$, $\mathrm{KCl} 0.05 \mathrm{~g}, \mathrm{NaCl}, 0.01 \%, \mathrm{FeSO}_{4}$. The condition of the fermentation medium is as fallows . $\mathrm{pH}, 6$ temperature $30^{\circ} \mathrm{C}$ and inoculums size is of $0.5 \mathrm{ml}$.

\section{EXTRACTION OF XYLANASE}

The samples were withdrawn periodically at $24 \mathrm{hrs}$ in aseptic condition. The extract was filtered through Whatman filter No.1. The clear extract was centrifuged at 2000-3000 rpm for $15 \mathrm{~min}$, supernatant were used as enzyme preparation. Thus prepared crude enzyme was used for assay of xylanase.

\section{ASSAY OF XYLANASE}

The xylanase activity was determined by measuring the release of reduced sugars from oat spelt Xylan $(1 \% \mathrm{w} / \mathrm{v})$ by dinitrosalicylic acid method ${ }^{7}$. The enzyme solution $(0.5 \mathrm{ml})$ and 0.5 substrate (xylan $1 \% \mathrm{w} / \mathrm{v}$ ) along with $1 \mathrm{ml}$ of buffer were taken in a test tube, the tubes were then allowed to stand at room temperature for $10 \mathrm{mins}$, and $3 \mathrm{ml}$ of dinitrosalicylic acid was added to arrest the reaction. After the addition of dinitrosalicylic acid, the tubes were placed in boiling water bath for $10 \mathrm{~min}$. The color which had developed was read at $540 \mathrm{~nm}$. A blank test tube was prepared by adding dinitrosalicylic acid prior to the addition of enzyme to the test tubes.

\section{INTERNATIONAL UNIT (IU)}

One unit of xylanase was defined as the amount of enzyme required to release $1 \mu \mathrm{mol}$ of xylose from oat spelt xylan in one minute under standard assay conditions.

\section{RESULTS AND DISCUSSION}

Thirty Penicillium citrinum isolates were isolated from different soil samples from Bangalore. All thirty isolates 
were named serially Aspergillus KSN1-KSN30 and used for screening of xylanase production by plate assay method. Out of thirty isolates Penicillium citrinum KGSN 05 were showed maximum enzyme hydrolytic zone were observed.

Fungal isolates were identified as Penicillium citrinum KGSN 05 identified in the laboratory. The extracted genomic DNA from Penicillium citrinum was represented in plate-1. Amplification of the ITS region (ITS1, ITS2, and 5.8 S rRNA Gene) were run on $1.2 \%$ Agarose gel electrophoresis showed PCR product of $\sim 600 \mathrm{bp}$ and represented plate-2. The aligned sequence of ITS region were represented in plate- 3 .
The evolutionary history was inferred by using the Maximum Likelihood method based on the Tamura-Nei model ${ }^{8}$. The tree with the highest log likelihood (759.4784) is shown. Initial tree(s) for the heuristic search were obtained automatically as follows. When the number of common sites was $<100$ or less than one fourth of the total number of sites, the maximum parsimony method was used; otherwise BIONJ method with MCL distance matrix was used. The analysis involved 11 nucleotide sequences. Codon positions included were $1 \mathrm{st}+2 \mathrm{nd}+3 \mathrm{rd}+$ Noncoding. All positions containing gaps and missing data were eliminated. There were a total of 489 positions in the final dataset. Evolutionary analyses were conducted in Molecular Evolutionary Genetics Analysis (MEGA5) Plate-4.

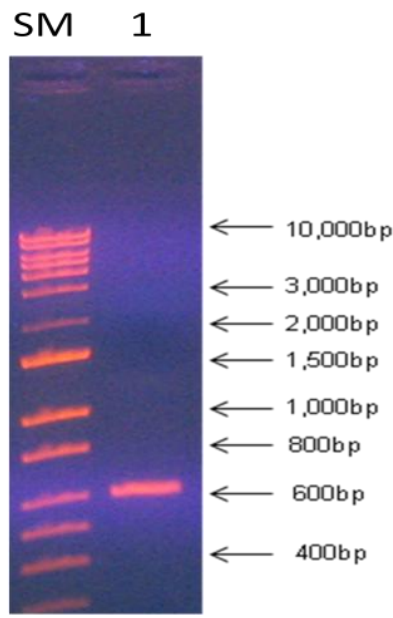

Plate-1: $0.8 \%$ Agarose gel electrophoresis of Fungal Genomic DNA. (Lane 1)
Plate-2: Agarose gel electrophoresis SM- standard marker.

Lane 1-sample PCR product of $\sim 600 \mathrm{bp}$

TGTTCTGTCAGACTCGGGGCCACCTCCCACCCGTGTTGCCCGAACCTATGTTGCCTCGGCGGGCCCCGCGCCCGCCGACGGC CCCCCTGAACGCTGTCTGAAGTTGCAGTCTGAGACCTATAACGAAATTAGTTAAAACTTTCAACAACGGATCTCTTGGTTCC GGCATCGATGAAGAACGCAGCGAAATGCGATAACTAATGTGAATTGCAGAATTCAGTGAATCATCGAGTCTTTGAACGCAC ATTGCGCCCTCTGGTATTCCGGAGGGCATGCCTGTCCGAGCGTCATTGCTGCCCTCAAGCCCGGCTTGTGTGTTGGGCCCCG TCCCCCCCGCCGGGGGGACGGGCCCGAAAGGCAGCGGCGGCACCGCGTCCGGTCCTCGAGCGTATGGGGCTTCGTCACCCG CTCTAGTAGGCCCGGCCGGCGCCAGCCGACCCCCAACCTTTAATTATCTCAGGTTGACCTCGGATCAGGTAGGGATACCCGC TGAACTTAAGCATATCAATAGGCGGAGGAACCTCGGGGCCCAACCTCCACCCGTGTTGCCCGAACCTATGTTGCCTCGGCG GGCCCCGCGCCGCGACGGCCCCTGAACGCTGTCTGAAATTGCAGTCTGAACCTATAACGAAATTAGTTAAAACTTTCAACA ACGGATCTCTTGGTTCCGCATCGATGAAGAACGCAGCGAAATGCGATAACTAATGTGAATTGCAGAAGTCGTGAATCATCG AGTCTTTGAACGCACATTGCGCCTCTGTATTTCGAGGGCATGCTGTTCGAGCGTCATTGCTGCCCTCAGCCCGCTGTGTGTGG GACCCCGTTACCGCAGGAAAACGGCCCGAATGCACGCGTACCGTCGATCTCGAGCCTATGAGACCTAGCCTTCGAGGATCA GACTGGTGCGACGTGCACGCGACCGTGTGGGACGGGCTCATCACACAAGCCTGGCTGATGCCAGTCATGACGCTCGACAGC ATGCCTCGAATAGCAGAGGCGCAATGTGCGTCCAAAGACTCGATGATTCACTGACTCTGCAATCACTTAGTATCGCATCGCT GCGTTCTTCATCGATGCGAAACCAAGAGATCCGTTGTGAAAGTTTAAACTAATTTCGTATAGGTCTCAGACTGCAACTTCAG ACAGCGTTCAGGGGCTGTCGCGGCGCGGGCCCGCCGAGGCAACATAGGTTCGGGCAACACGGGTGGAGGTTGGGCCCCGA GGGGCCCGCACTCGTAATGATCCTCATCAGCAGCAGTGTTTTTTGTCCATCGGGGGCCAACCTCCCACCCGTGTTGCCCGAA CCTATGTTGCCTCGGCGGGCCCCGCGCCCGCCGACGGCCCCCCTGAACGCTGTCTGAAGTTGCAGTCTGAGACCTATAACGA AATTAGTTAAAACTTTCAACAACGGATCTCTTGGTTCCGGCATCGATGAAGAACGCAGCGAAATGCGATAACTAATGTGAA TTGCAGAATTCAGTGAATCATCGAGTCTTTGAACGCACATTGCGCCCTCTGGTATTCCGGAGGGCATGCCTGTCCGAGCGTC ATTGCTGCCCTCAAGCCCGGCTTGTGTGTTGGGCCCCGTCCCCCCCGCCGGGGGGACGGGCCCGAAAGGCAGCGGCGGCAC CGCGTCCGGTCCTCGAGCGTATGGGGCTTCGTCACCCGCTCTAGTAGGCCCGGCCGGCGCCAGCCGACCCCCAACCTTTAAT TATCTCAGGTGACCTCGGATCAGGAAGGATCTCGG

Plate-3: Aligned sequence of ITS region 


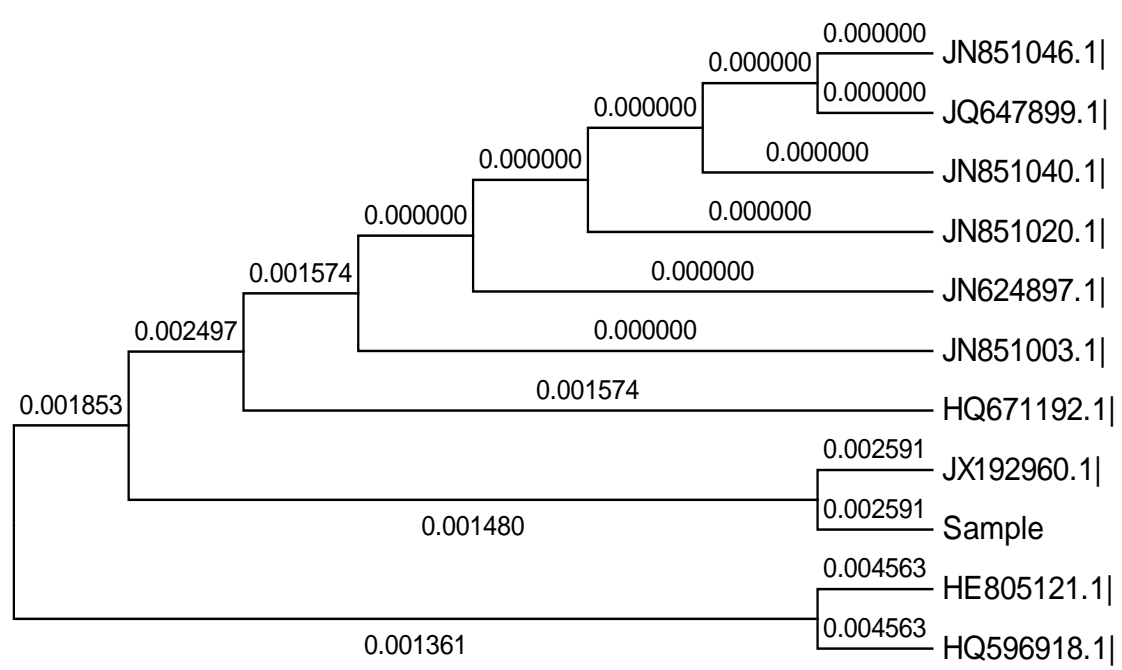

Plate-4: Phylogenetic tree

The results on the studies pertaining to the production of xylanase by Penicillium citrinum KGSN 05 on synthetic medium supplemented with different concentrations of various carbon sources like glucose (monosaccharide), maltose (disaccharide) and sucrose (disaccharide) are presented in Fig-1, Fig-2 and Fig-3 respectively.

The process economization for xylanase production with carbon sources supplemented to the production medium were carried out with concentration of $0.25 \%, 0.5 \%$, $0.75 \%$ and $1.0 \%$. The results revealed that all the carbon sources employed under the present study have enhanced the production of xylanase upto $0.5 \%$ of monosaccharide and disaccharides (glucose, maltose and sucrose) at $72 \mathrm{hrs}$ of fermentation, thereafter no significant production of xylanase was observed on all the days of fermentation period. In case of monosaccharides (glucose) the maximum xylanase production of 5.87 IU was observed at $0.5 \%$ and where as disaccharides like maltose yielded maximum xylanase of 4.65 IU.

Ana Cláudia Elias Pião Benedetti et al., ${ }^{9}$ suggest that extracellular xylanase activity in this fungus is induced by xylan and xylose (up to $1 \%$ ). However, at $2 \%$, xylose partially represses the enzyme. Pang Pei Kheng and Ibrahim ${ }^{10}$ reported xylose has been described as an effective inducer and carbon source for xylanase production. Our results are coincides with the Ana Cláudia Elias Pião Benedetti et $\mathrm{al}^{9}$.

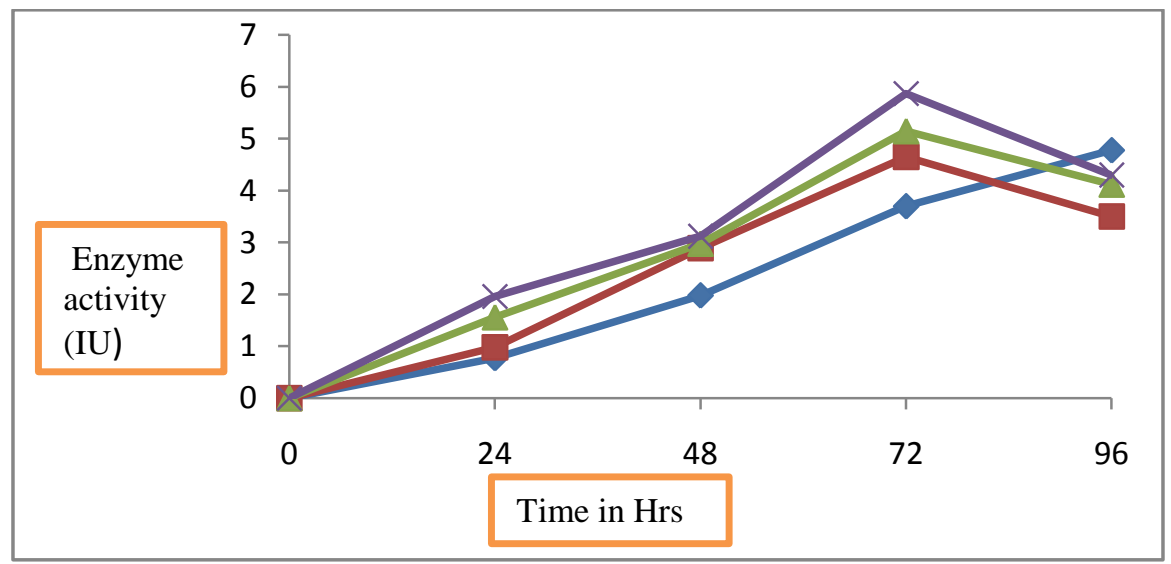

Figure 1: Effect of Glucose on Xylanase production 


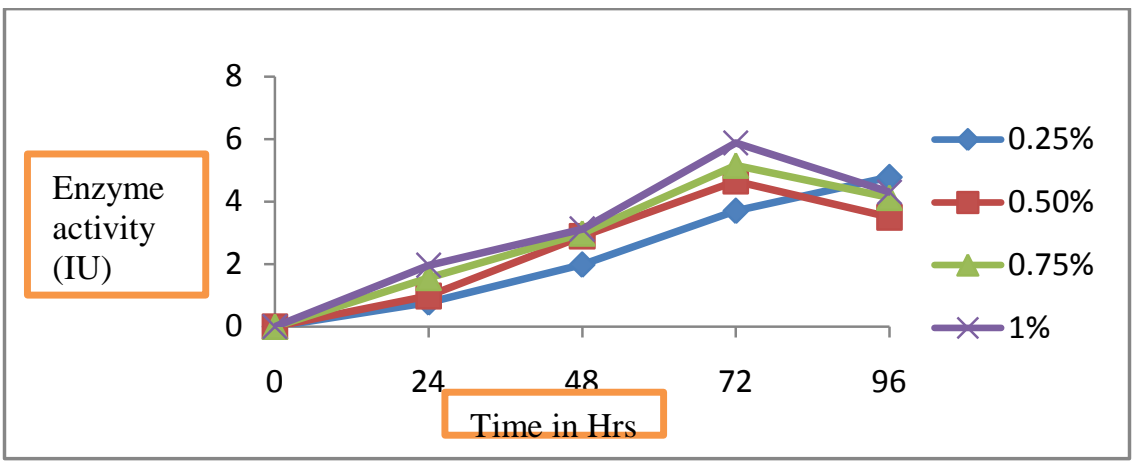

Figure 2: Effect of Maltose on Xylanase production

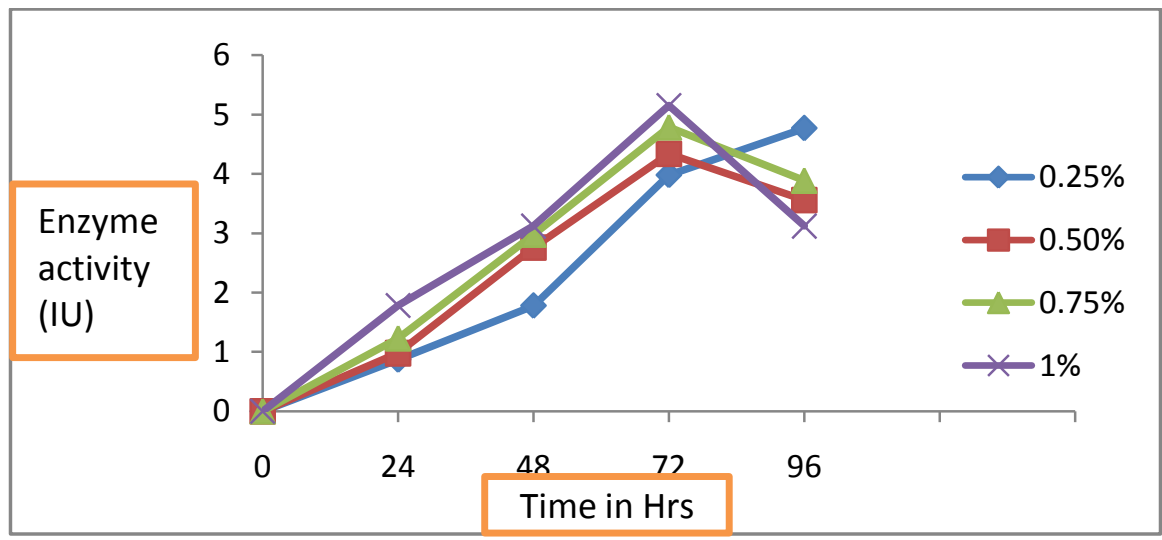

Figure 3: Effect of Sucrose on Xylanase production

\section{CONCLUSION:}

Among the thirty isolates Penicillium citrinum KGSN 05 were showed better xylanase production. The enhanced level of biosynthesis of xylanase observed by supplementation of carbon source such as glucose, maltose and sucrose have showed better yield under submerged fermentation by using synthetic medium.

\section{REFERENCES}

1. Subramaniyun S and Prema P. Biotechnology of microbial xylanases, enzymology, molecular biology and applications. Crit Rev. Biotechnol, 2002; 22;(1) 33.

2. Balaa A.B., Wouters J., Dogne S., Rossini C., Schaus J., Depiereux E., Vandenhaute J., Housen I. Identification, cloning, and expression of Sctalidium acidophillum XYLI gene encoding for acidophilic xylanase. Biosci. Biotechnol. Biochem. 2006; 70; 269.

3. Kulkarni N., Shendye A., Rao M. Molecular and biotechnological aspects of xylanases. FEMS Microbiol. Rev. 1999; 23; 411.

4. Dalboge H. Expression cloning of fungal enzyme genes; a novel approach for efficient isolation of enzyme genes of industrial relevance. FEMS Microbiol. Rev. 1997; 21; 2942.
5. Li L., Tian H., Cheng Y., Jiang Z., Yang S. Purification and characterization of a thermostable cellulose-free xylanase from the newly isolated Paecilomyces thermophila. Enzyme Microb. Technol. 2006; 38; 780

6. Dhulappa, A and Lingappa, K. Xylanase screening and biosynthesis from Aspergillus tamari. Int.J.Curr.Microbiol.App.Sci. 2013; 2(7); 79-83

7. Miller and Gail Lorenz. "Use of dinitrosalicylic acid reagent for determination of reducing sugar". Anal. Chem. 1959; 31 (3); 426-428.

8. Tamura K, Nei M Estimation of the number of nucleotide substitutions in the control region of mitochondrial DNA in humans and chimpanzees. Mol Biol Evol. 1993;10; 512-526.

9. Ana Claudia Elias Piao Benedetti ; Eliana Dantas da Costa, Caio Casale Aragon, Andrea Francisco dos Santos, Antonio Jose Goulart, Derlene Attili-Angelis, Rubens Monti.(2013). Low-cost carbon sources for the production of a thermostable xylanase by Aspergillus niger Rev Cienc Farm Basica Apl., 2013; 34(1):25-31.

10. Pang Pei Kheng and Ibrahim, C.O. Xylanase production by a local fungal isolate, Aspergillus niger USM AI 1 via solid state fermentation using palm kernel cake (PKC) as substrate. 2005; $27(2) ; 325-336$. 